\begin{tabular}{|c|cc|c|}
\hline PORT -SAID ENGINEERING RESEARCH JOURNAL & Faculty of Engineering -port said university \\
\hline
\end{tabular}

\title{
Advantage and Disadvantage of Colored Concrete in Structural Engineering
}

\author{
By Nesreen EL- Awadly ${ }^{1}$, Kamal Gad Sharobim ${ }^{2}$, N-A Hussein ${ }^{3}$
}

\begin{abstract}
:
This paper is about the impact of the colored pigments on the concrete and its various properties. A number of colored pigments found in the Egyptian markets were used; some of these pigments are made in China and others are made in Germany. The effects of these materials were studied on the fresh and hardened concrete, the consistency studied by slump test, the strengths studied by compressive strength test and the durability studied by abrasion test and permeability test. It is found from this research that colored pigments does not affect in the concrete mechanical properties in a danger way, Colored concrete must constructed with accuracy and with a good experience.
\end{abstract}

Key words: Colored concrete, Colored pigments, Iron Oxide, Stained concrete.

\section{INTRODUCTION}

Current colored concrete is used to make a great surface in civil construction. It is spread in the Arab and Gulf countries; the cause may be due to the increase of the standard of living, which leads to the attempt to reach the latest techniques in construction matters and finishing operations and decorations

The basic search work of this paper is to compare between the colored mixtures and the main mix, which have the same structural characteristics such as w/c ratio, the amounts of fine aggregate, the amount of coarse aggregate and the way of casting.

Despite the advantage of colored concrete, the scientific researches in this field are not widely presented as any other engineering fields, the point that confirmed from many engineering researchers.

Structural colored concrete is a material which offers different beauty patterns, breaks the monotony of structures, and can be more economical as a finish surface choice. Studies related to this kind of special concrete are innovative because there is both a lack of research and sparse bibliography on this subject, particularly in connection with durability. [1]

\footnotetext{
${ }^{1}$ B.Sc Civil Engineering, Faculty of Engineering,Port Said University, E-mail: zakarianesren@yahoo.com

2 Prof. of Civil Engineering Department, Faculty of Engineering, Suez Canal University, Ismailia, Egypt,

E-mail:k.sharobim@scuegypt.edu.eg

${ }^{3}$ Civil Engineering Department, Faculty of Engineering, Port Said University, Port Said, Egypt,

E-mail: Nourallah@psu.edu.eg.
}

The ability to color concrete in shades of yellow ,orange ,red, blue , and green makes structures more attractive and provides interesting design opportunities .The use of digitally controlled, accurate dosage technology enables the achievement of consistent pigmentation .Coloring concrete serves enhance the surroundings ,resulting in an urban landscape that is bold ,bright and uplifting. [2]

Colored concrete is one of the concrete types that need a special way of finishing and curing because any of these two factors may be the reason for colored concrete construction failure.

Colored surfaces must be cured carefully to produce uniform color; also the curing method must maintain uniform moisture content across the surface. If a surface sealer is to be applied, curing compounds will affect the adhesion and penetration of the sealer and must be completely degraded / removed from the surface prior to apply the sealer. [3]

Colored concrete is now used in several places such as crosswalk, indoor and outdoor of houses, kitchens, path rooms. In addition, its use in stamped and colored concrete crosswalks is increasingly popular. Colored concrete not only provides an aesthetically pleasing appearance, but also makes the crosswalk safer by serving as a permanent pavement marking. [4]

Standard Specification for pigments for Integrally Colored, ASTM C979-99. [5] presented the Chemical effect of iron oxide pigments (colored pigments ) .

M.J. Positieri and P. Helene(2008) made the following experimental program: Three groups of concretes have 
been proposed with distinct dry total aggregate/cement ratios. Each group consists of a standard reference of concrete family, which does not have pigment and three concretes families with different pigment colors [iron oxides], with the same workability, this makes up 12 different mixtures. [1]

The previous research makes concrete tests to compare between gray concrete and colored concretes such as compressive strength test, Water permeability test and void and water absorption test.This research result was as follow: all the concretes discussed have the same mortar content and workability and variable w/c, what means different compressive strength. The pigments shows not have any influence in compressive strength. The durability of colored concretes, particularly those depending directly on how easily aggressive agents can penetrate and percolated within the porous structure of concrete, enables us to state that the addition of pigments is beneficial to the durability of the concretes under study pursuant to prevailing testing conditions. [1]

M. Resheidat(2008) has the following experimental program: A number of specimens in the forms of cubes, cylinders and prisms were cast and properly cured, It is necessary to document the mechanical properties of the produced colored concrete aiming at laying out the basis for future development in terms of workability by using super plasticizers strength and may be self compacting colored concrete. As structural colored concrete, this experimental investigation was focused on twofold objectives; namely: the color of concrete and the strength of concrete that aimed to be used as a structural concrete. Accordingly, the properties of the produced colored concrete were described through the classical testing procedures for compression, flexure, direct tension, splitting and direct shear. [6]

This research has the following results: An acceptable compressive strength of this colored concrete was achieved, Other results for cubes in compression, splitting and flexure were very consistent with the norms. [6]

Other researches recommended some points about the characteristics of the concrete:

The amount of added coloring material should not exceed $10 \%$ by weight of the cement, because larger amounts of pigment may excessively reduce the concrete strength. Strong color can usually be produced with less than $10 \%$ of added pigment. Different color intensities are achieved by varying the amount of coloring material or by mixing two or more pigments. Red, tan, dark gray and other hues are produced very satisfactorily by using normal cement. However, admixtures that contain calcium chloride should be avoided since it can cause discoloration. [7]

Adding extra water to increase the slump may cause excessive bleeding and non-uniformity in color, and using any admixtures that contain calcium chloride should be avoided. Calcium chloride may cause salt deposits to be formed on the concrete surface and discolor it. [8]

The following study represents the colored concrete with unusual materials such as earthenware powder:

It is thought that reusing of waste colorful earthenware powder as admixture material of concrete is effective to color the concrete. After studying the mechanical properties and the color evaluation of colored concrete by using the earthenware powder were examined. As a result, the strength and coloring effect of concrete increased with the increase of the replacement ratio of the earthenware powder. Furthermore, the color of concrete using the red earthenware powder was satisfied with the color evaluation of the wall of temples and shrines in traditional area of Kyoto. [9]

There are three types of Colored pigments, and there is more than one way to perform colored concrete.

Liquid color is made by mixing powdered or semi-dried iron oxide with 30 to 40 percent of water, surfactants and stabilizers to form a "suspension.", Granules are made by mixing a binder and dispersant with the liquid color and spray drying the mixture. [10]

Powder type pigments are very fine grained powder even smaller than cement which leads to agglomeration and hooking when they are packed in large packages. Liquid color form is produced by dispersing pigments into the water by means of admixtures and it is dust free and it has high pigment content, low sedimentation property, and higher stability. Use of liquid color is recommended for very small mixing performance as it must be homogeneously distributed .Its transportation cost is higher as it is transported with water .The problem of presence of water can be solved by addition of antifreezes during winter. [11]

Automated coloring systems for ready-mixed concrete rely on computer technology to control the metering and dispensing of liquid colorants. [12]

A standard specification for certifying that pigments are water-soluble, water-wettable, light resistant ,alkali resistant ,stable under curing, and will not have a detrimental effect on concrete strength or consistency when mixed at recommended dosage rates. Iron oxides pigments that comply with ASTM C979 [5] can be produced in a synthetic process or refined form naturally occurring ore deposits. Today, synthetic pigments are the most widely used to color concrete. Iron oxides are popular for their wide range of colors, relatively low cost, stability against chemicals and weather exposure, and because they are non-toxic. [13] 


\section{Experimental work}

The Reference Mix (Control Mix) shall contain the quantities of constituent material (cement, water, fine aggregate and coarse aggregate)and without any colors or pigment, the colored mixtures have the same quantities of material but also have colored pigment

The amount of color that is added to the concrete mixtures is referred to as fine aggregate, since it would be relatively a small quantity and ensure that no mistakes happen, it is recommended to be used by weight not by volume.

Two kinds of cement are used, ordinary Portland cement and white Portland cement

The experiment of coloring was in laboratory to create colored concrete and to observe the results.

German colors are used in addition to Chinese production, so the used colors in this research will be four colors: Orange and red color of German manufacture, Blue and red color of Chinese manufacture

In addition to the white color resulted from white cement without adding colors (white).

Also the colors of plain concrete mix (control mix) without adding some colors by using plain Portland cement (grey). It has been selected several percentages of colored pigments in the ordinary Portland cement mixtures as follow:

The percentage of color of Chinese manufacture

1 - Color ( 1 ) red with a percentage of $5 \%, 10 \%, 15 \%$.

2 - Color (2) blue with a percentage of 5\%, 10\%, $15 \%$.

The percentage of color of German manufacture

3 - Color (3) orange with a percentage of $3 \%, 5 \%$.

4 - Color (4) red with a percentage of $3 \%, 5 \%$.

The percentages will be as follow with the white Portland cement is:

1- Color( 1)of Chinese manufacture is $10 \%$

2- Color(2) of Chinese manufacture is $10 \%$

3- Color (3) of German manufacture is 3\%, 5\%

4- Color (4) of German manufacture is 3\%, 5\%

The physical and mechanical properties of concrete ingredients namely aggregate, cement, and water are determined. These properties were determined according to the Egyptian Specifications.

Water used for mixing is clean drinking water free of impurities which comply with the requirement of the Egyptian code of practice for design of construction of concrete structure 203/2007.

Physical and mechanical prosperities of cement given in Table (1). The tested cement complies with the requirements of ESS 2421 part1-2005.
Natural crushed stone from Suez area was used as coarse aggregate, natural siliceous sand composed mainly of siliceous materials sand composed mainly materials was used as fine aggregate

Table (1) the physical and mechanical properties of OPC

\begin{tabular}{|c|c|c|}
\hline properties & Test result & $\begin{array}{c}\text { ESS2421 part1- } \\
\text { 2005. }\end{array}$ \\
\hline Initial $(\mathrm{min})$ & 95 & $<45 \mathrm{~min}$ \\
\hline Final (hrs) & 3.75 & $>10 \mathrm{hrs}$ \\
\hline Finesse by Blaine test $\left(\mathrm{cm}^{2 / \mathrm{gm}}\right)$ & 2970 & $<2500$ \\
\hline Soundness $_{\mathrm{mm}}$ & 1.0 & $>10 \mathrm{~mm}$ \\
\hline Compressive strength $^{2}$ & & \\
\hline 3 days $_{\mathrm{N} / \mathrm{mm}^{2}}{ }^{2}$ & $43 \sim 45$ & $>27$ \\
\hline 7 days \\
$\mathrm{N} / \mathrm{mm}^{2}$ & $63 \sim 66$ & $>36$ \\
\hline
\end{tabular}

Both fine and coarse aggregate are comply with the requirement of ESS1109/2002, physical properties and sieve analysis of aggregates that are shown in tables (2) to (5) respectively.

\section{Table (2) Properties of fine aggregates}

\begin{tabular}{|c|c|c|}
\hline Properties & Measured Value & ESS limits \\
\hline Compacted density, $\left(\mathbf{k g} / \mathbf{m}^{\mathbf{3}}\right)$ & 1790 & \\
\hline Loose density $\left(\mathbf{k g} / \mathbf{m}^{3}\right)$ & 1700 & \\
\hline Fineness modulus & 2.67 & $2.3 \sim 3.1$ \\
\hline Specific gravity & 2.50 & \\
\hline Fine material \%by volume & 1.0 & $>3 \%$ \\
\hline
\end{tabular}

Table (3) Grading of fine aggregates

\begin{tabular}{|l|c|c|c|c|c|c|}
\hline Sieve Size & $5 \mathrm{~mm}$ & $\begin{array}{c}2.36 \\
\mathrm{~mm}\end{array}$ & $\begin{array}{c}1.18 \\
\mathrm{~mm}\end{array}$ & $600 \mu \mathrm{m}$ & $300 \mu \mathrm{m}$ & $150 \mu \mathrm{m}$ \\
\hline \% passing & 100 & 93.5 & 81.3 & 50.6 & 6.40 & 1.00 \\
\hline ESS limits & $89-100$ & $65-100$ & $45-100$ & $25-80$ & $5-48$ & $0-15$ \\
\hline
\end{tabular}

Table (4) Properties of coarse aggregates

\begin{tabular}{|c|c|c|}
\hline Properties & Measured Value & ESS limits \\
\hline Specific gravity & 2.5 & \\
\hline Unit weight & 1.61 & \\
\hline Absorption \% & 1.85 & \\
\hline Crushing value \% & 14.39 & $<45$ \\
\hline Dust content \% & 0.55 & $<1 \%$ \\
\hline
\end{tabular}

Table (5) Grading of coarse aggregates

\begin{tabular}{|c|c|c|}
\hline Sieve Size mm & \% passing & ESS limits \\
\hline 19 & 100 & $95-100$ \\
\hline 16 & 60 & - \\
\hline 9.5 & 50 & $20-60$ \\
\hline 4.75 & 0 & $0-10$ \\
\hline
\end{tabular}

Some mixtures contain admixtures with specific amounts according to the type of admixture used in the research, the used admixtures has a commercial name (MC-Supper 41) it is complies with the requirements of the American Standard Specifications (ASTM C494Type F ) its properties shown in Table (6) 
Table (6) properties of super plasticizer

\begin{tabular}{|c|c|}
\hline Appearance & Clear Brown liquid \\
\hline Specific gravity at $\mathbf{2 5}^{\circ} \mathbf{C}$ & 1.165 \\
\hline Chloride content & Nil \\
\hline Air Entrainment & $<1 \%$ \\
\hline PH & $7 \pm 1$ \\
\hline
\end{tabular}

Concrete mixtures that are prepared are $21 \mathrm{mix}$, a number of concrete specimens have been prepared. Each one is standard cube in order to be used to carry out the permeability test at 180 day age and the compressive strength test in three ages, 7 days, 28 days, and 180 days.

In addition to preparing the specimens of abrasion test from each concrete mix; each one is a testing cube of standard dimensions on which the test of is performed. Therefore, there are a number of testing specimens, which represent the whole specimens used in research. One of

Absolute Volume Method is the way of design, the water cement ratio $=0.54$, the cement content in the mix $=350 \mathrm{~kg} / \mathrm{m}^{3}$, water amount is 189 litter in all mixtures without plasticizer the cubic meter components for each mix are shown in Table (7).

\section{Table (7) cubic meter components for each mix}

\begin{tabular}{|c|c|c|c|c|}
\hline $\begin{array}{c}\text { No } \\
\mathbf{1}\end{array}$ & Mix code & $\begin{array}{c}\text { Fine } \\
\text { Agg.(kg) }\end{array}$ & $\begin{array}{c}\text { Corse } \\
\text { Agg(kg) }\end{array}$ & $\begin{array}{c}\text { Color } \\
\text { pigment(kg) }\end{array}$ \\
\hline $\mathbf{2}$ & $5 \%$ R-CH-OPC $-O P C$ & 700 & 1120 & ----- \\
\hline $\mathbf{3}$ & $10 \%$ R-CH-OPC & 665.5 & 1120 & 17.5 \\
\hline $\mathbf{4}$ & $15 \%$ R-CH-OPC & 647.5 & 1120 & 35 \\
\hline $\mathbf{5}$ & $5 \%$ B-CH-OPC & 683.5 & 1120 & 17.5 \\
\hline $\mathbf{6}$ & $10 \%$ B-CH-OPC & 665 & 1120 & 35 \\
\hline $\mathbf{7}$ & $15 \%$ B-CH-OPC & 647.5 & 1120 & 53.5 \\
\hline $\mathbf{8}$ & $3 \%$ OR-GE-OPC & 689.5 & 1120 & 10.5 \\
\hline $\mathbf{9}$ & $5 \%$ OR-GE-OPC & 683.5 & 1120 & 17.5 \\
\hline $\mathbf{1 0}$ & $3 \%$ R-GE-OPC & 689.5 & 1120 & 10.5 \\
\hline $\mathbf{1 1}$ & $5 \%$ R-GE-OPC & 683.5 & 1120 & 17.5 \\
\hline $\mathbf{1 2}$ & $\begin{array}{c}\text { WH.C-NO } \\
\text { COLOR }\end{array}$ & 700 & 1120 & ----- \\
\hline $\mathbf{1 3}$ & $10 \%$ R-CH-WH.C & 665 & 1120 & 35 \\
\hline $\mathbf{1 4}$ & $10 \%$ B-CH-WH.C & 665 & 1120 & 35 \\
\hline $\mathbf{1 5}$ & $3 \%$ OR-GE-WH.C & 689.5 & 1120 & 10.5 \\
\hline $\mathbf{1 6}$ & $5 \%$ OR-GE-WH.C & 683.5 & 1120 & 17.5 \\
\hline $\mathbf{1 7}$ & $3 \%$ R-GE-WH.C & 689.5 & 1120 & 10.5 \\
\hline $\mathbf{1 8}$ & $5 \%$ R-GE-WH.C & 683.5 & 1120 & 17.5 \\
\hline $\mathbf{1 9}$ & AD-OPC-NO & 700 & 1247.11 & ---- \\
\hline $\mathbf{2 0}$ & $5 \%$ R -GE-AD- & 683.5 & 1247.11 & 17.5 \\
\hline $\mathbf{2 1}$ & $5 \%$ OPC $-G E-A D-$ & 683.5 & 1247.11 & 17.5 \\
\hline & OPC & & \\
\hline
\end{tabular}

them is standard cube $15 \times 15 \times 15 \mathrm{~cm}$ as well as standard cube $7 \times 7 \times 7 \mathrm{~cm}$.

The Steps of colored concrete Specimens Preparation were as follow: Preparing a plastic container in which the cement will be mixed well with the coloring oxide in their dry state, the plastic container is to be considered to be dry and clean.

First, the aggregate is put in the concrete mixer, then it is mixed in its dry state, the mixer is to be considered to be dry and clean. Then, the cement with color is to be well mixed with the aggregate. While doing this, the research notices that the cement color, white or gray, is not affected by the coloring oxide as they are in the dry state. Thus, the mix seems to be not colored, this must not affect the work, and the degree of the color added.

Water is added at its quantity specified in the design to the mixer; the color of the mix appears clearly, as soon as water is added.

The forms be prepared before casting as to be completely dry and clean, also be painted by the material used to remove forms easily. The idea of using the colored concrete is that it is the final surface of the concrete, and whether it is smooth, rocky, medium between either types, or anything else, figure (1) shows colored concrete standard casting forms.

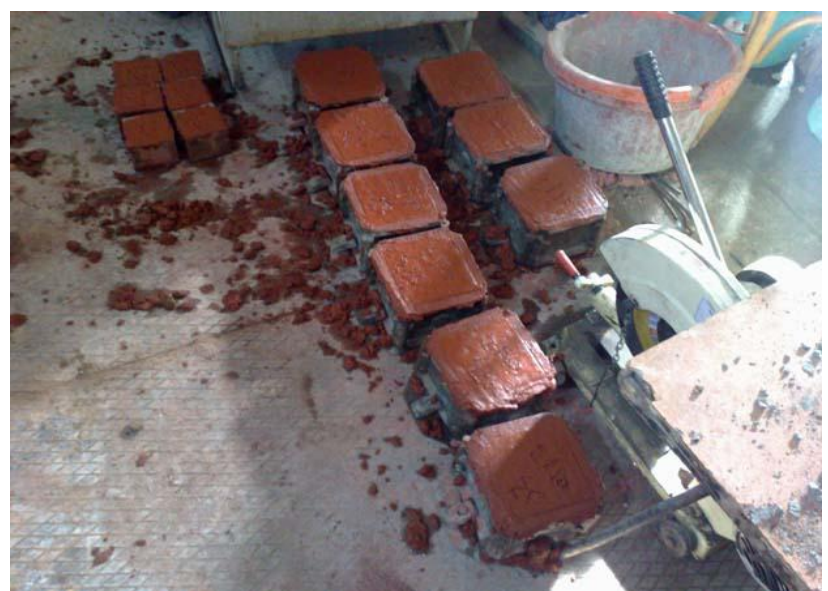

Fig (1) Red concrete specimens in the slandered forms after casting

After 24 hours of casting, the cubes are removed as they are hardened, the Specimens are immersed under 
water so that the processing stage is done; it is a very important stage in the concrete in general.

Concerning the mixtures of research, they include 21 essential mixtures. The characteristics of each mix in terms of four essential elements, which was designed on this basis, namely:

- The percentage of colored pigments

- Colors: there are four used colors GE refers to German manufacturer and $\mathrm{CH}$ refers to Chinese manufacturer.

- Colors: R refers to red color; B refers to blow color and OR refers to orange color.

- The type of cement: OPC refers to Ordinary Portland cement and WH.C refers to white cement.

- NO COLOR refers to not adding colors in the mix.

- AD refers to the existence of admixtures or not.

The slump test was carried out according to the Egyptian Standard Specification ESS 1658/1988[15], the compressive strength test was carried out according to Egyptian Standard Specification ESS 1658/1988, German permeability test was carried out, figure (2) shows the German permeability test done in colored concrete .

Abrasion test specimens are prepared in the shape of square pieces of a surface area $\left(6.4_{\mathrm{cm}} * 6.4_{\mathrm{cm}}\right)$, test specimens are dried in an oven for 24 hours standard proper equipment is used and the abrasion substance is quartz sand with a proper volume. figure (3) shows the abrasion test done in colored concrete .

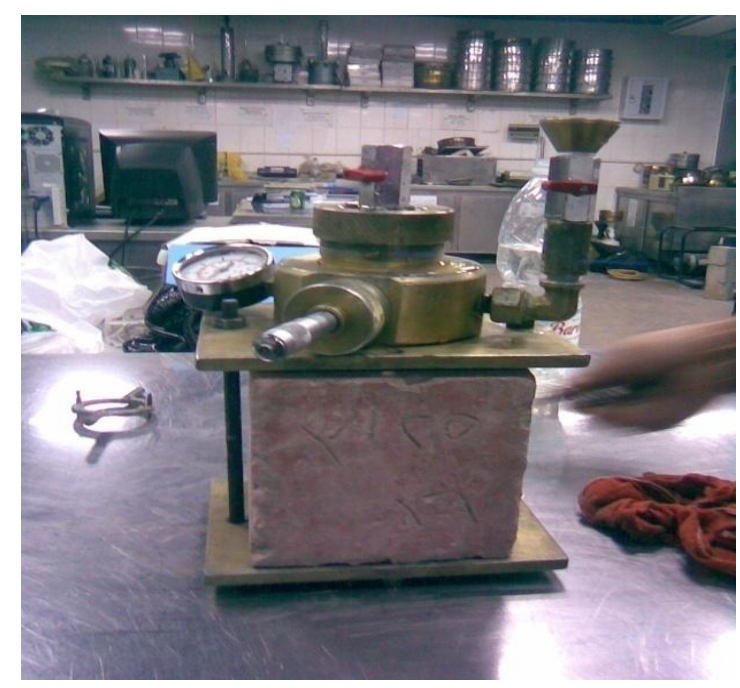

Fig (2) permeability test for hardened concrete

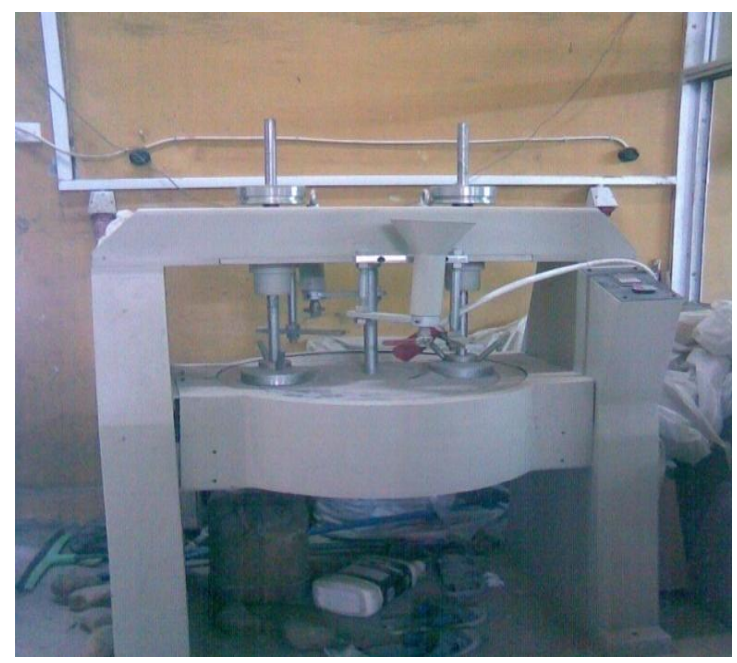

Fig (3) Abrasion test for hardened concrete

\section{Results and dissection}

Slump test result affected by addition of pigments in all colored mixtures, the highest colored slump was $85 \mathrm{~mm}$ and the lowest one was $75_{\mathrm{mm}}$ in the ordinary Portland cement mixtures, the highest colored slump was $75 \mathrm{~mm}$ and the lowest one was $65_{\mathrm{mm}}$ in the white Portland cement mixtures, table (8) shows the slump test results for every mix.

Table (8): Slump test results for research mixtures

\begin{tabular}{|c|c|c|c|c|c|}
\hline $\begin{array}{c}\text { Mix } \\
\text { no. }\end{array}$ & Mix code & $\begin{array}{l}\text { Slump } \\
(\mathrm{mm})\end{array}$ & $\begin{array}{l}\text { Mix } \\
\text { no. }\end{array}$ & Mix code & $\begin{array}{l}\text { Slump } \\
(\mathrm{mm})\end{array}$ \\
\hline 1 & No Color -OPC & 100 & 12 & $\begin{array}{c}\text { WH.C-NO } \\
\text { COLOR }\end{array}$ & 65 \\
\hline 2 & $5 \% \mathrm{R}-\mathrm{CH}-\mathrm{OPC}$ & 80 & 13 & $\begin{array}{c}\text { 10\%R-CH- } \\
\text { WH.C }\end{array}$ & 70 \\
\hline 3 & $10 \% \mathrm{R}-\mathrm{CH}-\mathrm{OPC}$ & 80 & 14 & $\begin{array}{c}\text { 10\%B-CH- } \\
\text { WH.C }\end{array}$ & 70 \\
\hline 4 & $15 \% \mathrm{R}-\mathrm{CH}-\mathrm{OPC}$ & 75 & 15 & $\begin{array}{c}\text { 3\%OR-GE- } \\
\text { WH.C }\end{array}$ & 75 \\
\hline 5 & $5 \% \mathrm{~B}-\mathrm{CH}-\mathrm{OPC}$ & 75 & 16 & $\begin{array}{c}\text { 5\%OR-GE- } \\
\text { WH.C }\end{array}$ & 75 \\
\hline 6 & $10 \% \mathrm{~B}-\mathrm{CH}-\mathrm{OPC}$ & 80 & 17 & 3\%R-GE-WH.C & 65 \\
\hline 7 & $15 \% \mathrm{~B}-\mathrm{CH}-\mathrm{OPC}$ & 75 & 18 & 5\%R-GE-WH.C & 65 \\
\hline 8 & 3\%OR-GE-OPC & 75 & 19 & $\begin{array}{l}\text { AD-OPC-NO } \\
\text { COLOR }\end{array}$ & 85 \\
\hline 9 & $5 \%$ OR-GE-OPC & 85 & 20 & $\begin{array}{l}\text { 5\% R -GE-AD- } \\
\text { OPC }\end{array}$ & 85 \\
\hline 10 & $3 \%$ R-GE-OPC & 75 & 21 & $\begin{array}{c}5 \% \text { OR-GE-AD- } \\
\text { OPC }\end{array}$ & 75 \\
\hline 11 & $5 \%$ R-GE-OPC & 75 & & & \\
\hline
\end{tabular}


Table (9): Compressive strength test results for research mixtures

\begin{tabular}{|c|c|c|c|}
\hline \multirow[t]{2}{*}{ Mix code } & \multicolumn{3}{|c|}{ Compressive strength $\left(\mathrm{kg} / \mathrm{cm}^{2}\right)$} \\
\hline & 7 day & 28 day & 180 day \\
\hline No Color -OPC & 236 & 368 & 411 \\
\hline 5\% R-CH-OPC & 239 & 354 & 415 \\
\hline $10 \%$ R-CH-OPC & 227 & 344 & 421 \\
\hline 15\% R-CH-OPC & 220 & 320 & 401 \\
\hline 5\% В-СН-ОРС & 220 & 332 & 380 \\
\hline 10\%B-CH-OPC & 200 & 313 & 373 \\
\hline 15\%B-СН-OPC & 201 & 303 & 365 \\
\hline 3\%OR-GE-OPC & 240 & 384 & 419 \\
\hline 5\%OR-GE-OPC & 241 & 361 & 409 \\
\hline 3\%R-GE-OPC & 222 & 350 & 401 \\
\hline 5\%R-GE-OPC & 226 & 329 & 382 \\
\hline WH.C-NO COLOR & 177 & 200 & 320 \\
\hline 10\%R-CH-WH.C & 128 & 180 & 292 \\
\hline 10\%B-CH-WH.C & 200 & 259 & 339 \\
\hline 3\%OR-GE-WH.C & 150 & 215 & 305 \\
\hline 5\% OR-GE-WH.C & 183 & 263 & 299 \\
\hline 3\%R-GE-WH.C & 153 & 268 & 360 \\
\hline 5\%R-GE-WH.C & 159 & 223 & 330 \\
\hline $\begin{array}{l}\text { AD-OPC-NO } \\
\text { COLOR }\end{array}$ & 268 & 375 & 435 \\
\hline 5\% R -GE-AD-OPC & 260 & 355 & 429 \\
\hline 5\% OR-GE-AD-OPC & 241 & 364 & 425 \\
\hline
\end{tabular}

Compressive strength results are shown in table (9), the results can represent the following points:

- The increasing of the strength after 180 days is so clear in all mixtures; these increases are reasonable to the strength at 7 and 28 days.

- Low strength of the White cement mixtures in the early age means that they are inferior to the normal cement mixtures with a note that it does not exceed $300 \mathrm{~kg} / \mathrm{cm}^{2}$ until the age 180 days (6 months).
- It is clear that Adding MC -41 of plasticizers affect so good on increasing strength especially after 180 days age.

- The impact of increasing the proportion of pigments to $15 \%$ compared with levels of $5 \%$ and $10 \%$ is so clear. The lowest proportion of pigments resulted in the highest comprehensive strength.

- The nearest value of comprehensive strength of the colored mixtures to the control one without colors is the mix, which has $3 \%$ pigments.

- Colored pigments may affect in the strength, but we cannot say that. Colored pigments have big or dinger affect in the concrete strength.

Curves from figure (3)to figure (9) show the relationship between colored mixtures age and strength the behavior of colored mixtures is very near to control mix.

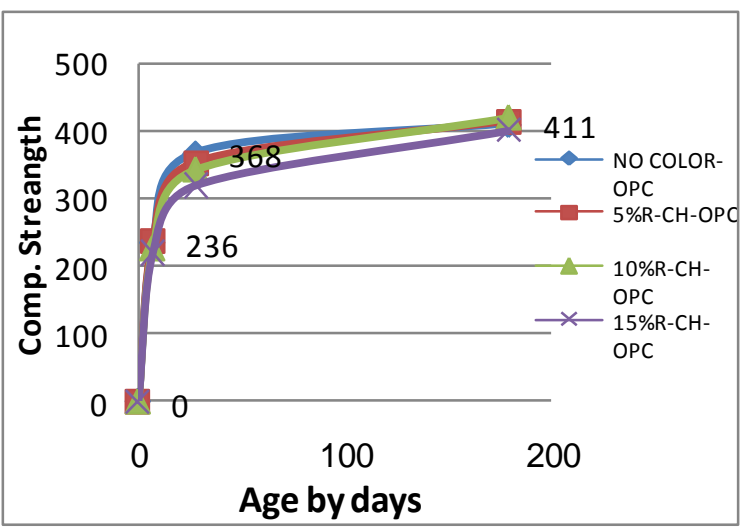

Fig.(4) Effect of Red Chinas Pigments (5\%, 10, 15\%) used with Ordinary Portland cement On the strength.

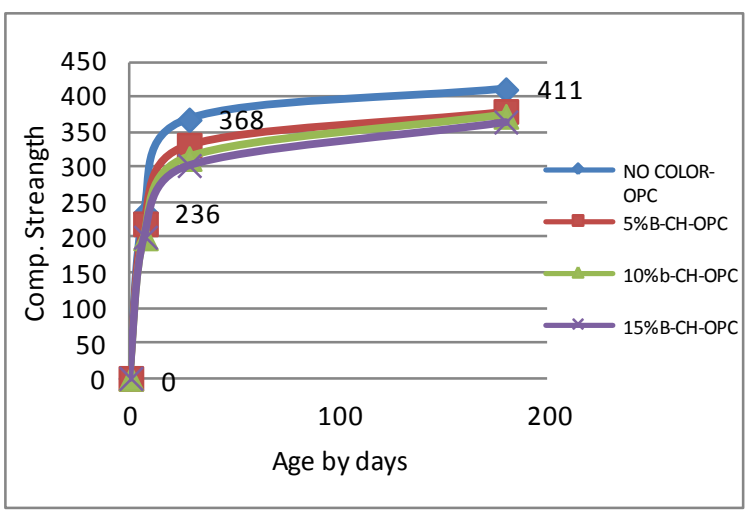

Fig. (5) Effect of Blue Chinese Pigments (5\%, 10, 15\%) used with Ordinary Portland cement On the strength. 


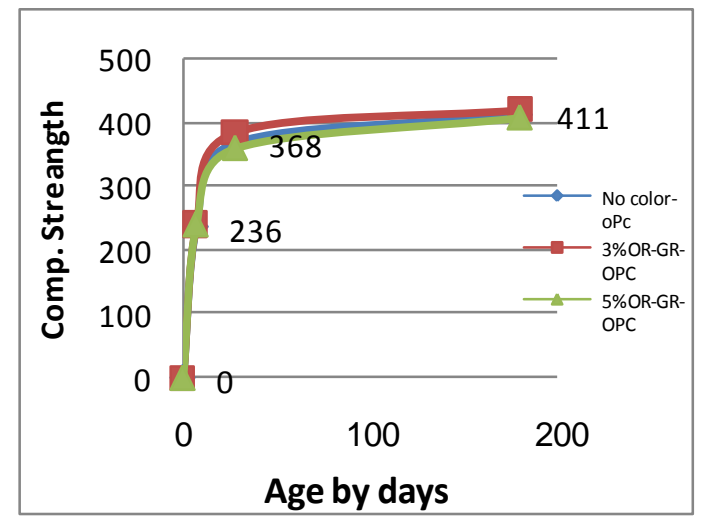

Fig (6) Effect of Orange German Pigments (3\%, 5\%) used with Ordinary Portland.

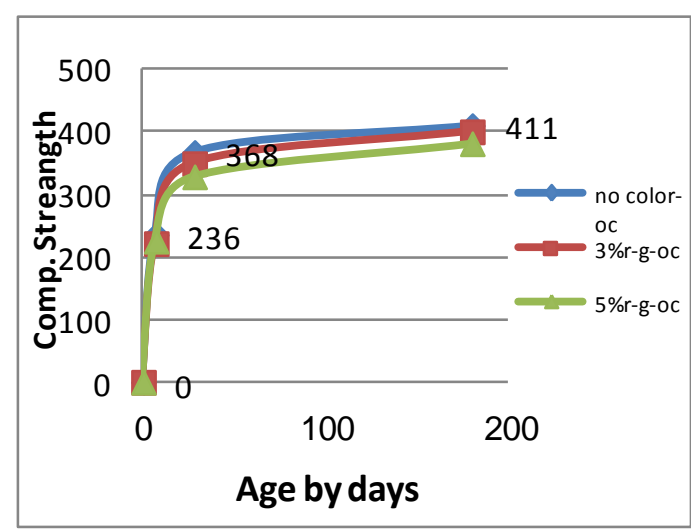

Fig (7) Effects of Red German Pigments (3\%, 5\%) used with Ordinary Portland cement on the strength

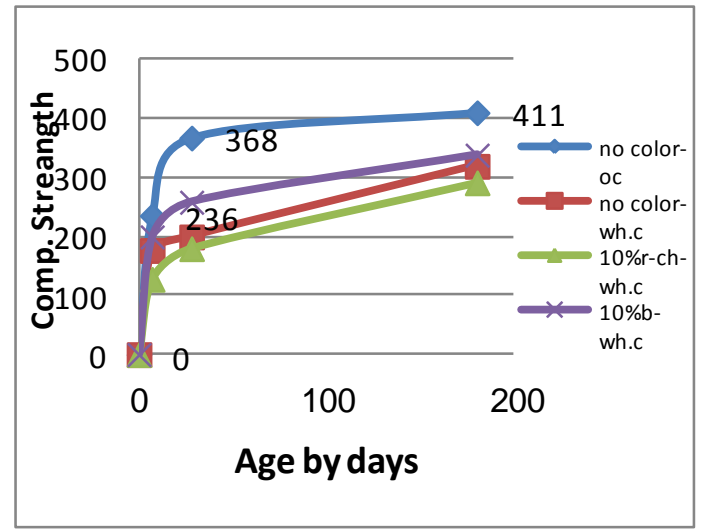

Fig (8) Effects of Chinese Pigments (10\% Red, 10\% Blue) used with white Portland cement \&white mix without color

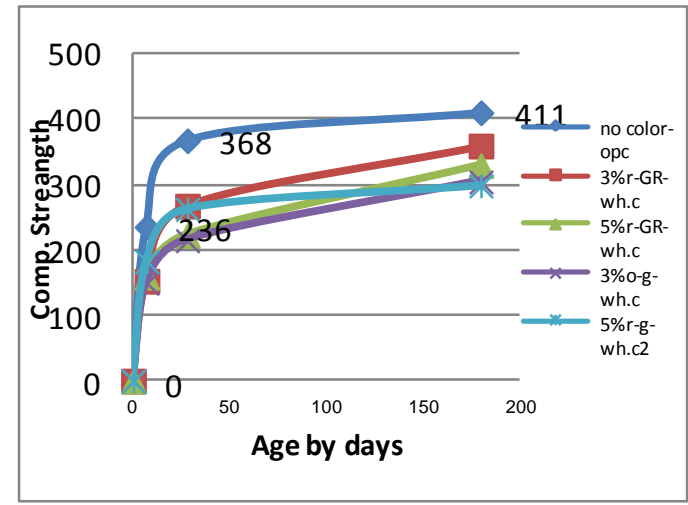

Fig (9) Effect of German Pigments (3\%, 5\%) used with white Portland cement on the strength

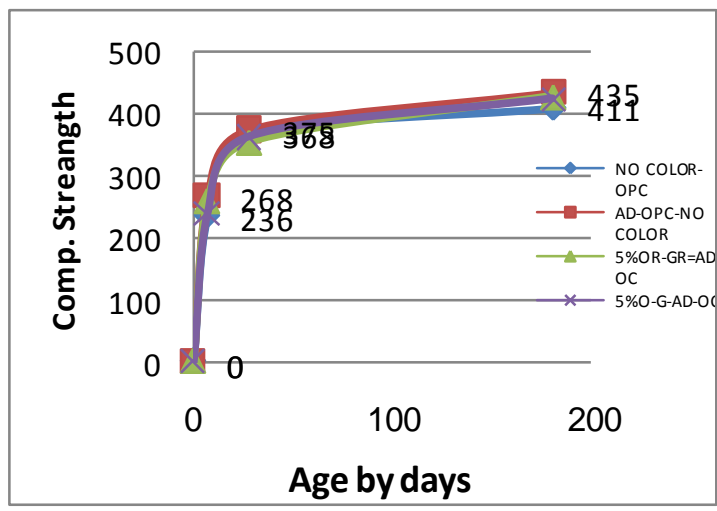

Fig (10) Effects of German Pigments (5\% Orange, 5\% Red) used with Ordinary Portland cement and with high plasticizer admixtures on the strength

Abrasion Test used for comprehension in general ,The research compare between the control mix witch without any admixture and the other colored mixtures.

Table (10) shows the Abrasion test results for tow specimens from every mix.

Most of the change in weight in all mixtures does not exceed 12 grams. In addition, most of thickness loss dose not reach $(1 \mathrm{~mm}$.

There are no significant differences between the result of the control mix and the other mixtures.

There are no special effects of the colored pigments that can record, depending on result of the test. 
Table (10) Abrasion test results for tow specimens from every mix.

\begin{tabular}{|c|c|c|}
\hline Mix code & $\begin{array}{l}\text { Average weight } \\
\operatorname{loss}(\text { gm) }\end{array}$ & $\begin{array}{l}\text { Average } \\
\text { thickness } \\
\text { loss }(\mathrm{mm})\end{array}$ \\
\hline No Color -OPC & 5.65 & 0.46 \\
\hline 5\%R-CH-OPC & 11.15 & 0.91 \\
\hline $10 \%$ R-CH-OPC & 7.1 & 0.57 \\
\hline 15\%R-CH-OPC & 6.65 & 0.54 \\
\hline 5\% В-СH-OPC & 5.15 & 0.42 \\
\hline 10\%B-CH-OPC & 7.0 & 0.57 \\
\hline 15\% B-CH-OPC & 6.8 & 0.55 \\
\hline 3\%OR-GE-OPC & 9.8 & 0.8 \\
\hline 5\%OR-GE-OPC & 8.00 & 0.65 \\
\hline 3\%R-GE-OPC & 8.3 & 0.67 \\
\hline 5\%R-GE-OPC & 7.4 & 0.58 \\
\hline WH.C-NO COLOR & 7.0 & 0.57 \\
\hline 10\%R-CH-WH.C & 8.7 & 0.71 \\
\hline 10\%B-CH-WH.C & 8.1 & 0.66 \\
\hline 3\%OR-GE-WH.C & 8.0 & 0.65 \\
\hline 5\%OR-GE-WH.C & 10.0 & 0.67 \\
\hline 3\%R-GE-WH.C & 7.2 & 0.58 \\
\hline 5\%R-GE-WH.C & 8.3 & 0.67 \\
\hline $\begin{array}{c}\text { AD-OPC-NO } \\
\text { COLOR }\end{array}$ & 5.05 & 0.4 \\
\hline 5\%R -GE-AD-OPC & 6.9 & 0.56 \\
\hline $\begin{array}{c}\text { 5\% OR-GE-AD- } \\
\text { OPC }\end{array}$ & 6.4 & 0.55 \\
\hline
\end{tabular}

Table (11) shows the results of permeability test for every specimen of each mix with comprehension between control mix and other mixtures in the three state of casting (ordinary Portland cement,white cement ,ordinary Portland cement with admixtures).

The highest coefficient of permeability is $\left(-0.15 * 10^{-8}\right)$ and there is no big change in The coefficient of permeability after adding the pigments .Also ,there is no change between the result of OPC colored concrete and the concrete made with white cement with and without colors.
Table (11) permeability test result for all mixtures.

\begin{tabular}{|c|c|c|}
\hline Mix code & $\begin{array}{c}\text { Permeability } \\
\text { coefficient } \\
\left({ }^{* 10^{-8}} \mathrm{~mm} / \mathrm{sec}\right)\end{array}$ & $\begin{array}{c}\text { Change in } \\
\text { permeability } \\
\text { coefficient }\end{array}$ \\
\hline No Color -OPC & 0.96 & ---- \\
\hline 5\%R-CH-OPC & 0.97 & 0.01 \\
\hline 10\%R-CH-OPC & 0.91 & -0.05 \\
\hline $15 \%$ R-CH-OPC & 0.95 & -0.01 \\
\hline 5\%В-СН-ОРС & 0.99 & 0.03 \\
\hline 10\%B-CH-OPC & 0.9 & -0.06 \\
\hline 15\%B-CH-OPC & 0.99 & 0.03 \\
\hline 3\%OR-GE-OPC & 0.95 & 0.01 \\
\hline 5\%OR-GE-OPC & 0.98 & 0.02 \\
\hline 3\%R-GE-OPC & 0.98 & 0.02 \\
\hline 5\%R-GE-OPC & 0.89 & 0.07 \\
\hline WH.C-NO COLOR & 1.02 & 0.06 \\
\hline 10\%R-CH-WH.C & 1.02 & 0.06 \\
\hline 10\%B-CH-WH.C & 1.06 & 0.1 \\
\hline 3\%OR-GE-WH.C & 0.99 & 0.03 \\
\hline 5\%OR-GE-WH.C & 1.10 & 0.05 \\
\hline 3\%R-GE-WH.C & 0.98 & 0.02 \\
\hline 5\%R-GE-WH.C & 1.11 & 0.15 \\
\hline AD-OPC-NO COLOR & 0.81 & -0.15 \\
\hline 5\% R -GE-AD-OPC & 0.88 & -0.08 \\
\hline 5\%OR-GE-AD-OPC & 0.81 & -0.15 \\
\hline
\end{tabular}

\section{CONCLUSION}

The purpose of the experimental work involved in this research is to study the advantage and the disadvantage of colored concrete in the structural and architectural engineering projects. From the experimental study and the previous work, the following conclusion can be concerned.

1- Difference in compressive strength between colored concrete and gray concrete can be neglected by time and in the hardened concrete late age. 
2- The effect of changing the percentage of colored pigments in the mixtures as $5 \%, 10 \%$ and $15 \%$ Can give this result; compressive strength decreases with adding high amount of colored pigments.

3- Increase the colored pigment may reduce the concrete slump and make some change in concrete workability.

4- Little percentage of pigments can make big difference in the concrete color and change its color from gray to other color.

5- The lowest percentage of color gives the nearest value of compressive strength of the control mix.

6- Compressive strength for mixtures which mixed with German pigment is more close to the gray mixtures than the mixtures which mixed with Chinese pigment.

7- High quality of pigments gives good results.

8- Using white cement makes the concrete color more clear and strong, but mixtures with white cement have low compressive strength.

9- The effect of colors on the strength is small even in white cement mixtures, but there is big difference in compressive strength between mixtures with ordinary Portland cement and mixtures with white cement.

10- Using white cement in colored concrete should be in the non construction projects.

11- Iron oxide pigments admixtures should not exceed $10 \%$ of cement content. It should comply with ASTM C 979.

12- Mixtures with plasticizers admixtures have high strength than the main mix without admixtures, especially in 180 days age .

13- The strength reduction due to colors can be disappear by time if concrete casted with admixtures.

14- The highest percentage of weight loss is $28.9 \mathrm{gm}$ it doesn't exceed $1.45 \%$ and the lowest percentage of weight loss is $0.26 \%$.and the value of percentage of weigh loss for the control mix (without colors) is $0.28 \%$

15- In all mixtures the average weight loss is too small.
16- Abrasion test result can't record big effect of colored pigment.

17- Finishing is an important factor in colored concrete.

18- There is no construction risk with using colored pigment.

19- saving by colored concrete may reach $24 \%$ when the projects have good planning

20- Colored concrete type must be chosen carefully, constructed with accuracy and with a good experience to match the right design.

\section{REFERENCES}

[1] M.J. Positieri and P. Helene, "Physicomechanical Properties and Durability of Structural Colored Concrete", American Concrete Institute ,ACI Special Publication,(253SP),pp,176-193, (2008)

[2] Kussmaul,A.,Bzdega, E., "Coloured Concrete Choices" ,Concrete(London),37(10),pp.50-52.,(2003).

[3] " Colouring ,Stencilling and Stamping Concrete Flatwork"",Briefing,01,Cement Concrete\& Aggregates Australia, June(2007),

[4] American Concrete Pavement Association, "Facts about concrete for Intersection ",(August 2004), volume40,Number 3.

[5] Standard Specifications for Integrally Colored Concrete ,ASTM C979-99. American Society for Testing and Materials, 1993.

[6] M. Resheidate, "Development of Colored Concrete in Jordan", INTERNATIONAL CONFERENCE ON CONSTRUCTION AND BUILDING TECHNOLOGY.ICCBT -A-(13)PP153-164,(2008).

[7] American Concrete Pavement Association,

" INCORPORATING COLORED CROSSWALKS IN CONCRETE PAVEMENTS",Number 503, (March 2004).

[8] Buehrer, Richard, " Tips On Integrally Colored Concrete", Concrete Construction -World of Concret ,32(5),pp.445447, (1987).

[9] Inoue,M.,Hirao,K.,Okamoto,T.,Kojima,T," Mechanical properties and color of colored concrete by using waste earthenware powder",Zairo/Journalof the Society of Materials Since,Japan,57(10),pp.1019-1024, (2008). 
[10] "Manufacturing Colored Concrete Masonry", (July 2008) ROCK WOOD Pigment.

[11] Weber,P. ,"Pigments for coloring concrete Powder-Liquid-Granules-Compact

pigment", Concrete Precasting Plant and Technology,72(7),pp. 14-21,(2006).

[12] Chusid,m. ,Coloring Ready-Mixed Concrete",Concrete International,Vol.25,No.12,pp92-93,(2003).

[13] "Issues Affecting Color Durability in Concrete Masonry, Segmental Retaining Wall Units and Unit Concrete Pavers" ,National Concrete Masonry Association Concrete Color Durability Task Group,MR16,July 2002 